\title{
Simple models to predict vaginal delivery and spontaneous fetal occiput rotation based on intrapartum ultrasound and maternal characteristics
}

\author{
Cheng Chen ${ }^{1}$, Xiaoxing Zhang ${ }^{2}$, Xiaohan Guo ${ }^{1}$, Hangkai Bao ${ }^{1}$, Peiying Luo ${ }^{2}$, Huaqin \\ Yang $^{2}$, Yali Wang ${ }^{3}$, Yimin Zhou ${ }^{1}$, Xiaofu Yang ${ }^{1}$, Xia Ying ${ }^{1}$, baihui zhao ${ }^{2}$, and Qiong Luo ${ }^{1}$ \\ ${ }^{1}$ Womens Hospital, Zhejiang University School of Medicine \\ ${ }^{2}$ Zhejiang University \\ ${ }^{3}$ Changxing Maternity and Child Health Care Hospital
}

April 8, 2021

\begin{abstract}
Objective: To develop the prediction models for identifying fetal occiput rotation and vaginal delivery based on intrapartum sonographic findings. Design: Prospective observational study. Setting: Hangzhou, China. Population: Nulliparous women with a singleton cephalic presentation at term. Methods: Serial intrapartum ultrasonography were performed in the latent phase (T1) and every three hours after that (T2, T3 and T4). The managing clinicians performed paired digital vaginal examinations to assess labor progress. Main Outcome Measures: Delivery mode and successful internal fetal head rotation to the occiput anterior (OA) position. Results: 614 women were included, of whom 524 underwent vaginal delivery, and 90 required cesarean section. The percentage of women with fetuses in non-occiput anterior position at the latent phase was $53.9 \%$ (331 cases), as 257 women underwent spontaneous rotation to OA position before delivery, 74 were with persistent occiput posterior or transverse position. We developed a model on the basis of the maternal height and middle angel to predict the spontaneous fetal occiput rotation, with the area under the receiver operating characteristic curve (AUC) was 0.667 (95\%CI 0.583-0.751). Moreover, a prediction model based on the maternal height and angle of progression to evaluate whether women underwent vaginal delivery was also developed, of which the AUC was 0.738(95\% CI: 0.763-0.793). Both models showed satisfactory calibration. Conclusion: Simple models based on maternal characteristics and intrapartum ultrasound findings might provide useful information for predicting vaginal delivery and internal fetal occiput rotation.
\end{abstract}

Title:Simple models to predict vaginal delivery and spontaneous fetal occiput rotation based on intrapartum ultrasound and maternal characteristics

\section{Authors}

Cheng Chen*,1, Xiaoxin Zhang+,1, Xiaohan Guo*, Hangkai Bao++, Peiying Luo+, Huaqin Yang+, Yali Wang§, Yimin Zhou++, Xiaofu Yang*, Xia Ying*, Baihui Zhao*, Qiong Luo*

\section{Affiliations}

*Department of Obstetrics, Women's Hospital, Zhejiang University School of Medicine, Hangzhou, China

+Zhejiang University School of Medicine, Hangzhou, China

++ Department of Ultrasound, Women's Hospital, Zhejiang University School of Medicine, Hangzhou, China SSChangxing Maternity and Child Health Care Hospital, Huzhou, China 
Authors contributed equally to this study.

\section{Correspondence to:}

Pro Q. Luo, Department of Obstetrics, Women's Hospital, Zhejiang University School of Medicine, Hangzhou, 310006, China; (E-mail: luoq@zju.edu.cn)

Dr. B. Zhao Department of Obstetrics, Women's Hospital, Zhejiang University School of Medicine, Hangzhou, 310006, China (E-mail: zhaobh@zju.edu.cn)

Running title: Delivery prediction models, intrapartum ultrasound

\section{ABSTRACT}

Objective:To develop the prediction models for identifying fetal occiput rotation and vaginal delivery based on intrapartum sonographic findings.

Design: Prospective observational study.

Setting: Hangzhou, China.

Population: Nulliparous women with a singleton cephalic presentation at term.

Methods: Serial intrapartum ultrasonography were performed in the latent phase (T1) and every three hours after that (T2, T3 and T4). The managing clinicians performed paired digital vaginal examinations to assess labor progress.

Main Outcome Measures: Delivery mode and successful internal fetal head rotation to the occiput anterior (OA) position.

Results: 614 women were included, of whom 524 underwent vaginal delivery, and 90 required cesarean section. The percentage of women with fetuses in non-occiput anterior position at the latent phase was $53.9 \%$ (331 cases), as 257 women underwent spontaneous rotation to OA position before delivery, 74 were with persistent occiput posterior or transverse position. We developed a model on the basis of the maternal height and middle angel to predict the spontaneous fetal occiput rotation, with the area under the receiver operating characteristic curve (AUC) was 0.667 (95\% CI 0.583-0.751). Moreover, a prediction model based on the maternal height and angle of progression to evaluate whether women underwent vaginal delivery was also developed, of which the AUC was 0.738(95\% CI: 0.763-0.793). Both models showed satisfactory calibration.

Conclusion: Simple models based on maternal characteristics and intrapartum ultrasound findings might provide useful information for predicting vaginal delivery and internal fetal occiput rotation.

Key words: Prediction model, intrapartum ultrasound, angle of progression, midline angle, vaginal delivery, fetal occiput rotation

\section{Tweetable abstract}

Simple models based on maternal height and ultrasound findings can predict the delivery mode and internal fetal head rotation.

\section{INTRODUCTION}

Operative deliveries are associated with increased maternal (obstetric hemorrhage, perineal injuries, wound infection) ${ }^{1,2}$ and neonatal morbidity (neonatal seizures, and intracranial hemorrhage) ${ }^{2-6}$. It is important to monitor labor progress to prevent these maternal and neonatal complications ${ }^{7}$. The conventional assessment currently relies on a serial digital examination, which has been demonstrated to be subjective, imprecise, and poorly reproducible ${ }^{8,9}$. Furthermore, digital vaginal examinations can also cause discomfort ${ }^{10}$ and may introduce infection ${ }^{9}$. Intrapartum ultrasonographic examinations have been introduced to complement assessments of labor progress ${ }^{11}$. 
Occiput posterior (OP) and occiput transverse (OT) positions account for 15 to $49 \%$ at the onset of labor 12-15, and in most cases, the fetal head will rotate spontaneously to the occiput anterior (OA) positions. Accumulating evidence implicates the persistent OP or OT position is associated with obstetric complications, including prolonged labor, operative delivery, postpartum hemorrhage and third or fourth-degree perineal lacerations ${ }^{16-18}$. The spontaneous internal rotation of the fetal occiput from the transverse or posterior position to the anterior position is associated with multiparity, a maternal age of fewer than 35 years, maternal stature, BMI, and newborn birth weight $(<4000 \mathrm{~g}){ }^{14,19,20}$. However, there is still no model, which can help predict successful fetal head rotation during the delivery.

In the last decade, various sonographic parameters have been proposed, including the angle of progression $(\mathrm{AoP})^{21}$, head-perineum distance (HPD) ${ }^{22}$ and midline angle (MLA) ${ }^{23}$. Several studies have reported that intrapartum ultrasonography is a reliable and noninvasive approach for determining fetal head position, station and descent ${ }^{24-27}$. The AoP has been used to assess fetal head station and be predictive of spontaneous vaginal delivery or successful instrumental vaginal delivery ${ }^{28-31}$, and the MLA was associated with the fetal head station and rotation ${ }^{11}$.

In the majority of studies, a single assessment of sonographic parameters was performed in either the first or second labor phase ${ }^{30,32-35}$. Moreover, few studies have developed predictive models associated with successful internal rotation and vaginal delivery. Therefore, the primary aim of the present study was to assess serial intrapartum ultrasound measurements at different time points during delivery for the prediction of the delivery mode in nulliparous women. A secondary aim was to develop a model to predict successful internal fetal occiput rotation.

\section{METHODS}

This prospective, longitudinal observational, single-center study was conducted in the Women's Hospital at Zhejiang University School of Medicine in Hangzhou, China, between May 2020 and November 2020. Nulliparous women with a singleton pregnancy in a cephalic presentation at term (37 or more full weeks of gestation) attempting vaginal birth were eligible for the study. Women were excluded if they were under 18 years of age, had intrauterine death or had emergencies (e.g., premature placental abruption, uterine rupture, cardiac disease of New York Heart Association (NYHA) grade 3 or 4, eclampsia). We also excluded the cases if they required cesarean deliveries purely because of fetal distress. The study was approved by the local ethics and research committees (IRB-20200148-R). Written consent was obtained from the women who agreed to participate.

\section{Ultrasound assessments}

The ultrasound assessments were carried out by four operators (X.X.Z., H. K. B., P.Y.L. and H.Q.Y.), who have had at least three year's obstetric ultrasound experience and were not involved in the clinical management of the recruited women. When the participants were in the semirecumbent position with an empty bladder, a two-dimensional transperineal ultrasonography scan was performed to assess the AoP, MLA and HPD using a GE Logiq V2 ultrasound system (GE Healthcare, USA) with a 2-5 MHz curvilinear transducer, as previously described ${ }^{21-23}$. The fetal occiput position was assessed transabdominally or transperineally ${ }^{36}$, and the position was defined using the 12-hour clock system (see SUS1) ${ }^{37}$. The AoP is the angle between the long axis of the pubic bone and the leading part of the fetal skull in the midsagittal plane ${ }^{21}$ (Figure 1a). The HPD is the shortest distance between the outer bony limit of the fetal skull and the perineum in the transverse plane ${ }^{22}$ (Figure $1 \mathrm{~b}$ ). The MLA is defined as the angle between the anteroposterior axis of the maternal pelvis and the midline of the fetal head ${ }^{23}$ (Figure 1c).

Digital examinations were performed by experienced obstetricians or midwives to assess cervical dilation, fetal head position and fetal head station before the ultrasonographic scans. The fetal head station was defined as the distance from the lowest part of the fetal head to the ischial spine (i.e., from -3 to +3 , with 0 at the ischial spine). The interval between the paired examinations was no more than ten minutes, and the researchers were blinded to the findings of both examinations. The first intrapartum ultrasonographic examination was performed during the first stage of labor when the cervix was fully effaced and dilated by 
at least 3-4 $\mathrm{cm}$ but no more than $6 \mathrm{~cm}$ (latent phase) (T1), and intrapartum ultrasonographic scans were performed every three hours after that (T2, T3 and T4) until delivery.

The clinical team followed the standard local protocol of the research unit to manage labor progress. With a fully effaced cervix and cervical dilation of at least $3 \mathrm{~cm}$, the women in labor were admitted to the predelivery room for continuous fetal heart monitoring. Labor augmentation with oxytocin was considered if there was suboptimal uterine power and unsatisfactory progress, as demonstrated by a partogram, and there was no evidence of obstructed labor. Failure to progress was defined as longer than 12 hours in the latent phase or cervix failed to dilate at a rate of $1 \mathrm{~cm}$ per hour for at least 2 hours.

Maternal clinical data, such as age, gestational age at delivery, height, body mass index (BMI), induced or spontaneous labor, premature rupture of the membrane, the use of epidural anesthesia, labor augmentation with oxytocin, the final mode of delivery and the indication for operative delivery, were recorded. Data on the neonatal outcomes were also collected: sex, birth weight, Apgar scores after 1 and 5 minutes and the admission of the newborn to the neonatal unit. Gestational age was determined by the date of the first day of the last menstrual period and confirmed by the first-trimester ultrasound measurement of crown-rump length ${ }^{38}$. BMI was calculated according to the standard formula, and overweight was defined as BMI [?] $25 \mathrm{~kg} / \mathrm{m}^{2}$. Successful internal rotation was defined as the fetal head rotating to the occiput anterior (OA) position from a non-occiput anterior (non-OA) position (transverse or posterior) during the labor. Vaginal delivery in our unit included spontaneous and operative delivery using forceps.

\section{Calculation of sample size}

We assumed that the non-OA (OP and OT) prevalence during the first stage of labor was $60 \%$. We hypothesized that the rate of spontaneous internal rotation to the OA position would be $80 \%$ in the group, and the proportions of cesarean delivery in the non-OA position and OA position were $30 \%$ and $10 \%$, respectively. The total estimated sample size was 507 by accepting an alpha risk of 0.05 (two-sided) and a power of $80 \%$. Finally, we increased the number by $20 \%$ (634 women) to compensate for the dropout rate and any secondary exclusion.

\section{Statistical analysis}

Descriptive statistics were calculated, and the data are presented as the means (standard deviations [SDs]) or medians (ranges) for numeric variables. Comparisons of normally and nonnormally distributed continuous variables between study groups were performed using the Kruskal-Wallis test. Categorical variables are reported as numbers (percentages) and were compared by Fisher's exact test. Multivariable logistic regression analyses were performed to control potential cofounders and predict the successful fetal head rotation and vaginal delivery. The variables chosen in these logistic models were significant or marginally significant $(\mathrm{P}<0.1)$ in univariate analysis and were described in the previous studies ${ }^{20,39}$. Discrimination (the ability of the model to differentiate between the presence and absence of the event) was assessed by the area under the receiver operating characteristic curve (AUC). While calibration was assessed with calibration plots to measure how well the predicted outcome of the model agrees with the observed outcome. Statistical results with two-sided $\mathrm{P}$ values were reported, and a value of $\mathrm{P}<0.05$ was considered statistically significant. Statistical analyses were performed using Statistical Package for Social Sciences (SPSS) version 26 (IBM, Armonk, NY, USA) and R statistical software, version 4.0.3.

\section{RESULTS}

\section{Maternal characteristics}

A total of 634 nulliparous women were recruited, fifteen of whom were excluded because of incomplete data, and five withdrew due to discomfort during the ultrasound examination. Of the remaining 614 women, 524 $(85.3 \%)$ women underwent vaginal delivery and $90(14.7 \%)$ were required cesarean delivery. The percentage of women with fetuses in non-OA position at the first time of ultrasound examination was $53.9 \%$ (331 cases) in our study, as $159(25.9 \%)$ cases were in the OP position and $172(28.0 \%)$ were OT position. The main characteristics of the participants are shown in Table 1. 


\section{Comparison of clinical findings and ultrasound parameters by the mode of delivery}

The maternal and neonatal demographic characteristics compared between the vaginal delivery and cesarean delivery groups are shown in Table S1. There were no significant differences between these two groups, except for maternal height $(161.2+-4.6$ vs. $158.8+-5.1 \mathrm{~cm}, \mathrm{P}<0.001)$ and neonatal birth weight $(3390.5+-366.7$ vs. $3550.7+-380.4 \mathrm{~g}, \mathrm{P}<0.001$ ) (Table S1). Focusing on the sonographic parameters, the women who underwent vaginal delivery had a significantly larger AoP compared with the women who required cesarean section over time (Table 2). For HPD measurements, the cesarean delivery group showed significantly longer distance than did the vaginal delivery group (Table 2). Accounting for MLA, the vaginal delivery group showed comparable measurements to the cesarean delivery group initially (T1: $55.27+-27.36$ vs. 60.09+27.93deg; $\mathrm{P}=0.201$ ), whereas from three hours afterward, a significantly narrower angle was observed among the women who achieved vaginal delivery (T2: $47.42+-27.36$ vs. $68.18+-25.49 \mathrm{deg}, \mathrm{P}<0.001$; T3: $38.96+-$ 24.37 vs. $63.18+-30.79 \mathrm{deg} ; \mathrm{P}=0.004$ ) (Table 2).

\section{A simple model to predict the internal rotation}

A total of 257(77.6\%) women with a fetus in non-OA position during the latent phase underwent spontaneous rotation to OA position before delivery; however, 74 (22.4\%) were persistent OP or OT position. According to the occurrence of internal fetal head rotation, the individual characteristics were similar besides maternal height (161.0+-4.4 vs. $159.7+-5.2 \mathrm{~cm} ; \mathrm{P}=0.022)$ (Table S2). The multivariable logistic regression analysis demonstrated that the MLA (adjusted odds ratio [aOR]: 1.021, 95\% confidence interval [CI]:1.008-1.034) and maternal height (aOR: 1.107, 95\% CI:1.026-1.195) were the significant predictors of spontaneous fetal occiput rotation after adjusting for maternal age, gestational age, overweight, premature rupture of the membrane, labor induction, oxytocin augmentation and the use of epidural analgesia (Table S3). The final model that predicted internal fetal head rotation based on MLA at the first ultrasound scan and the maternal height was shown in Table 3, which obtained the AUC was 0.667 (95\% CI, 0.583-0.751; P <0.001) (Figure 2). The calibration curve shows good agreement between predicted and observed probabilities for the occurrence of spontaneous fetal head rotation (Figure 3(a)).

\section{A simple model to predict vaginal deliveries}

We performed a forward multivariate logistic regression analysis model that included the factors associated with the delivery mode in the univariate analysis $(\mathrm{P}<0.1)$. In this model, the AoP and maternal height were the independent factors associated with the mode of delivery after adjustment for confounders, including maternal age, gestational age, overweight (BMI[?]25 Kg/m²), premature rupture of the membrane, labor induction and oxytocin augmentation (Table S4). The combination of maternal height and the AoP could evaluate whether women were to undergo vaginal delivery, yielding an AUC of 0.738 (95\% CI, 0.763-0.793; $\mathrm{P}<0.001)$ at T1, $0.820(95 \% \mathrm{CI}, 0.752-0.888 ; \mathrm{P}<0.001)$ at T2 and $0.940(95 \% \mathrm{CI}, 0.885-0.995 ; \mathrm{P}<0.001)$ at T3 (Figure 4), respectively. Figure 3(b) showed the optimal calibration of the prediction model. This model was also suitable for women with fetuses in the occiput posterior or transverse position at the latent phase, yielding AUC $0.725(95 \% \mathrm{CI}, 0.649-0.801 ; \mathrm{P}<0.001)$ at T1 and $0.790(95 \% \mathrm{CI}, 0.705-0.874 ; \mathrm{P}<0.001)$ at T2, respectively (Figure $\mathrm{S} 2)$.

\section{DISCUSSION}

\section{Main Findings}

In the present study, we performed intrapartum ultrasonographic assessments of fetal head station and position, which differed significantly at various times during the labor. We developed a binary logistic regression model based on maternal height and angle of progression to predict $73.8 \%$ of vaginal deliveries at the latent labor phase. Moreover, a simple prediction model combining middle angel and maternal height for estimating the spontaneous fetal head rotation was also obtained. Because these two models both require only two parameters (one clinical variable and one intrapartum ultrasound parameter) that can be easily acquired, we suppose both models can be applied in any delivery unit.

\section{Strengths and Limitations}


The strengths of our study include the following: (1) this study is a prospective longitudinal study that measured ultrasound parameters of the fetal head station and position throughout the first and second labor stages in women with singleton pregnancies at term. (2) In this double-blinded study, the researchers and the managing clinicians were both blinded to the respective findings to avoid potential bias. (3) New objective and simple models based on the ultrasound parameters and clinical variables were shown to predict the internal fetal head rotation and delivery mode. However, we do acknowledge some limitations. Firstly, our study population included only Chinese women, and our results might not be representative of other ethnic populations. Secondly, neonatal birth weight is also a significant risk factor according to the mode of delivery in our observational study; however, we did not introduce this item as a predictive factor because of lacking a precise method to estimate the fetal weight before delivery. Furthermore, we should carry out the external validation of the prediction model.

\section{Interpretation (in light of other evidence)}

Non-occiput anterior (transverse or posterior) positions are associated with a high risk of cesarean section, operative vaginal delivery and other peripartum complications, including third- or fourth-degree perineal lacerations, postpartum hemorrhage and chorioamnionitis ${ }^{13,18,40,41}$. Compared with neonates born in the OA position, neonates born in a non-occiput anterior position have a lower Apgar score, a higher risk of neonatal intensive care unit admissions and higher rates of birth trauma ${ }^{18,19}$. The incidence of persistent OP position is between $5 \%$ and $12 \%^{12}, 18,42$, and that of persistent OT position varies from $3 \%$ to $8 \% 13,40,43$. A study by Petitjean et al. ${ }^{44}$ identified oxytocin augmentation, excessive gestational weight gain, direct OP position and macrosomia as independent factors associated with non-OA to OA rotation during the first stage of labor. In our study, maternal height is the single individual factor associated with internal fetal occiput rotation. On the other hand, the degree of fetal head rotation, as measured by the MLA, was parallel between vaginal and cesarean delivery groups at first. However, the MLA of the women who experienced vaginal delivery was narrower subsequently, indicating the occurrence of spontaneous rotation.

Moreover, we develop a simple model based on the intrapartum sonographic parameter and maternal characteristic to predict spontaneous fetal head rotation in the first stage of labor. We think this finding might provide the clinicians an opportunity to take earlier action to reduce the obstetric complications associated with persistent OP and OT positions.

Accumulating studies showed that maternal and neonatal characteristics, including parity, maternal age, height, BMI, neonatal birth weight and fetal head position, are independent factors that affect the mode of delivery ${ }^{28,45,46}$. Burke et al. ${ }^{47}$ reported a risk prediction model for cesarean delivery using five parameters (maternal age, height, BMI, fetal head circumference and fetal abdominal circumference), with excellent discrimination (Kolmogorov- Smirnov, D statistic, 0.29; 95\% CI, 0.28- 0.30). Furthermore, Eggebo et al. ${ }^{39}$ introduced intrapartum ultrasound to developed another risk score based on maternal characteristics (gestational age, maternal weight, BMI and cervical dilatation), occiput position and intrapartum findings (head perineal distance and caput succedaneum) to predict vaginal birth, which yielded an AUC of 0.853 (95\%CI, 0.678-1.000). Our study illustrated a much simple prediction model based on only two parameters (maternal stature and AoP) for evaluating the delivery mode in the nulliparas in the first stage of labor. We started the intrapartum ultrasound assessment during the latent phase (cervical dilatation less than $6 \mathrm{~cm}$ ), which allowed clinicians to identify early the women who required cesarean delivery. We caution that the knowledge derived from our model should not alter obstetric decision making. However, our study might provide useful information about the chance of spontaneous rotation and vaginal birth, allowing appropriate interventions at the proper time.

\section{CONCLUSION}

In conclusion, our study provides simple models based on maternal characteristics and intrapartum ultrasound findings that can predict the chance of vaginal birth and successful internal fetal head rotation in nulliparous women. We suppose these models can be implemented in any delivery unit.

\section{Disclosure of Interests}


The authors report no conflict of interest. Completed disclosure of interest forms are available to view online as supporting information.

\section{Contribution to Authorship}

Concept and design: CC, XXZ, XHG, BHZ and QL.

Data acquisition: HKB, YMZ, HQY, PYL and YLW.

Statistical analysis: CC, XXZ, XFY and XY

Drafting of manuscript: CC, BHZ and QL.

Review of manuscript: all authors.

\section{Details of Ethics Approval}

Ethical approval for the study was obtained from the Ethics Committee of Women's Hospital, Zhejiang University School of Medicine on 25 May 2020 (Number IRB-20200148-R).

\section{Funding:}

The study was supported by Nature Science Foundation of Zhejiang Province (Grants: LY20H040009), and State Key Foundation of Zhejiang Province (Grants: WKJ-ZJ-2126).

\section{Acknowledgment}

We thank all the women and physicians who participated in this study.

\section{Legends}

Figure 1. Sonographic parameters of fetal head descent and rotation: (a) The angle of progression (AoP) in the transperineal longitudinal plane; (b) The head-perineum distance (HPD) measured on a sagittal scan and (c) the midline angle in the transperineal axial plane.

Figure 2. Receiver operating characteristic curve for the prediction model of the midline angle combined with the maternal height. The area under the curve (AUC) for the prediction of successful fetal head rotation was 0.667 (95\% CI, 0.583-0.751; $\mathrm{P}<0.001)$.

Figure 3. Calibration curves for prediction models. (a) Model of fetal occiput rotation; (b) Model of vaginal delivery.

Figure 4. Receiver operating characteristic curve of the combination of maternal height and angle of progression (AoP) for predicting vaginal delivery at different scan intervals. The first scan time (T1) was at the latent labor phase (red line). Subsequent scans were performed at 3 hours intervals (T2, blue line; T3, green line). The areas under the curves (AUCs) for the prediction model were 0.738 (95\% CI, 0.763-0.793; $\mathrm{P}<0.001)$ at $\mathrm{T} 1,0.820(95 \% \mathrm{CI}, 0.752-0.888 ; \mathrm{P}<0.001)$ at $\mathrm{T} 2$ and $0.940(95 \% \mathrm{CI}, 0.885-0.995 ; \mathrm{P}<0.001)$ at T3, respectively.

Table 1 Maternal and newborn characteristics of participants

Table 2 The angle of progression (AoP), head-perineum distance (HPD) and midline angle (MLA) at different time points, according to the mode of delivery

Table 3 Final logistic regression models to predict spontaneous fetal occiput rotation and vaginal delivery

\section{Supporting information}

The following supplementary materials are available for this article:

Figure S1. Classification of fetal occiput position based on 12-hour clock face. 
Figure S2. Receiver operating characteristic curve of the model for predicting vaginal delivery in nulliparous women with fetuses in the occiput posterior or transverse position at latent phase.

Table S1. Maternal and neonatal characteristics of the study population, according to the mode of delivery.

Table S2. Maternal and neonatal characteristics of the study population, according to internal rotation.

Table S3. Maternal and neonatal characteristics of the study population, according to internal rotation.

Table S4. Logistic regression analysis for the prediction of delivery mode, according to serial ultrasound evaluations

\section{References}

1. Lisonkova S, Lavery JA, Ananth CV, Chen I, Muraca G, Cundiff GW, et al. Temporal trends in obstetric trauma and inpatient surgery for pelvic organ prolapse: an age-period-cohort analysis. Am J Obstet Gynecol. 2016 2016/08/01/;215(2):208-12.

2. Gimovsky AC, Berghella V. Randomized controlled trial of prolonged second stage: extending the time limit vs usual guidelines. Am J Obstet Gynecol. 2016 2016/03/01/;214(3):361-6.

3. Demissie K, Rhoads GG, Smulian JC, Balasubramanian BA, Gandhi K, Joseph KS, et al. Operative vaginal delivery and neonatal and infant adverse outcomes: population based retrospective analysis. BMJ. 2004;329(7456):24-9.

4. Contag SA, Clifton RG, Bloom SL, Spong CY, Varner MW, Rouse DJ, et al. Neonatal outcomes and operative vaginal delivery versus cesarean delivery. Am J Perinatol. 2010;27(6):493-9.

5. Murphy DJ, Liebling RE, Verity L, Swingler R, Patel R. Early maternal and neonatal morbidity associated with operative delivery in second stage of labour: a cohort study. Lancet. 2001;358(9289):1203-7.

6. Walsh CA, Robson M, McAuliffe FM. Mode of delivery at term and adverse neonatal outcomes. Obstet Gynecol. 2013;121(1):122-8.

7. World Health Organization partograph in management of labour. World Health Organization Maternal Health and Safe Motherhood Programme. Lancet. 1994;343(8910):1399-404.

8. Dupuis O, Silveira R, Zentner A, Dittmar A, Gaucherand P, Cucherat M, et al. Birth simulator: Reliability of transvaginal assessment of fetal head station as defined by the American College of Obstetricians and Gynecologists classification. Am J Obstet Gynecol. 2005 2005/03/01/;192(3):868-74.

9. Buchmann EJ, Libhaber E. Accuracy of cervical assessment in the active phase of labour. BJOG. 2007;114(7):833-7.

10. Seval MM, Yuce T, Kalafat E, Duman B, Aker SS, Kumbasar H, et al. Comparison of effects of digital vaginal examination with transperineal ultrasound during labor on pain and anxiety levels: a randomized controlled trial. Ultrasound Obstet Gynecol. 2016;48(6):695-700.

11. Ghi T, Eggebo T, Lees C, Kalache K, Rozenberg P, Youssef A, et al. ISUOG Practice Guidelines: intrapartum ultrasound. Ultrasound Obstet Gynecol. 2018;52(1):128-39.

12. Lieberman E, Davidson K, Lee-Parritz A, Shearer E. Changes in fetal position during labor and their association with epidural analgesia. Obstet Gynecol. 2005 May;105(5 Pt 1):974-82.

13. Cheng YW, Shaffer BL, Caughey AB. Associated factors and outcomes of persistent occiput posterior position: A retrospective cohort study from 1976 to 2001. Journal of maternal-fetal and neonatal medicine. 2006 Sep;19(9):563-8.

14. Sizer AR, Nirmal DM. Occipitoposterior position: associated factors and obstetric outcome in nulliparas. Obstet Gynecol. 2000 2000/11/01/;96(5, Part 1):749-52. 
15. Choi SK, Park YG, Lee DH, Ko HS, Park IY, Shin JC. Sonographic assessment of fetal occiput position during labor for the prediction of labor dystocia and perinatal outcomes. Journal of maternal-fetal and neonatal medicine. 2016;29(24):3988-92.

16. Fitzpatrick M, McQuillan K, O'Herlihy C. Influence of persistent occiput posterior position on delivery outcome. Obstet Gynecol. 2001 Dec;98(6):1027-31.

17. Carseldine WJ, Phipps H, Zawada SF, Campbell NT, Ludlow JP, Krishnan SY, et al. Does occiput posterior position in the second stage of labour increase the operative delivery rate? Aust N Z J Obstet Gynaecol. 2013 Jun;53(3):265-70.

18. Senecal J, Xiong X, Fraser WD. Effect of fetal position on second-stage duration and labor outcome. Obstet Gynecol. 2005 Apr;105(4):763-72.

19. Cheng YW, Shaffer BL, Caughey AB. The association between persistent occiput posterior position and neonatal outcomes. Obstet Gynecol. 2006 Apr;107(4):837-44.

20. Desbriere R, Blanc J, Le Du R, Renner JP, Carcopino X, Loundou A, et al. Is maternal posturing during labor efficient in preventing persistent occiput posterior position? A randomized controlled trial. Am J Obstet Gynecol. 2013 Jan;208(1):60.e1-8.

21. Barbera AF, Pombar X, Perugino G, Lezotte DC, Hobbins JC. A new method to assess fetal head descent in labor with transperineal ultrasound. Ultrasound Obstet Gynecol. 2009;33(3):313-9.

22. Eggebo TM, Gjessing LK, Heien C, Smedvig E, Okland I, Romundstad P, et al. Prediction of labor and delivery by transperineal ultrasound in pregnancies with prelabor rupture of membranes at term. Ultrasound Obstet Gynecol. 2006;27(4):387-91.

23. Ghi T, Farina A, Pedrazzi A, Rizzo N, Pelusi G, Pilu G. Diagnosis of station and rotation of the fetal head in the second stage of labor with intrapartum translabial ultrasound. Ultrasound Obstet Gynecol. 2009;33(3):331-6.

24. Ghi T, Youssef A, Maroni E, Arcangeli T, De Musso F, Bellussi F, et al. Intrapartum transperineal ultrasound assessment of fetal head progression in active second stage of labor and mode of delivery. Ultrasound Obstet Gynecol. 2013 Apr;41(4):430-5.

25. Bellussi F, Ghi T, Youssef A, Salsi G, Giorgetta F, Parma D, et al. The use of intrapartum ultrasound to diagnose malpositions and cephalic malpresentations. Am J Obstet Gynecol. 2017 Dec;217(6):633-41.

26. Gustapane S, Malvasi A, Tinelli A. The use of intrapartum ultrasound to diagnose malpositions and cephalic malpresentations. American journal of obstetrics and gynecology. 2018 2018/05/01/;218(5):540-1.

27. Sainz JA, Garcia-Mejido JA, Aquise A, Borrero C, Bonomi MJ, Fernandez-Palacin A. A simple model to predict the complicated operative vaginal deliveries using vacuum or forceps. Am J Obstet Gynecol. 2019 Feb;220(2):191-3.

28. Tse WT, Chaemsaithong P, Chan WWY, Kwan AHW, Huang J, Appiah K, et al. Labor progress determined by ultrasound is different in women requiring cesarean delivery from those who experience a vaginal delivery following induction of labor. Am J Obstet Gynecol. 2019 2019/10/01/;221(4):331-5.

29. Chaemsaithong P, Kwan AHW, Tse WT, Lim WT, Chan WWY, Chong KC, et al. Factors that affect ultrasound-determined labor progress in women undergoing induction of labor. Am J Obstet Gynecol. 2019 2019/06/01/;220(6):591-2.

30. Chan VYT, Lau WL, So MKP, Leung WC. Measuring angle of progression by transperineal ultrasonography to predict successful instrumental and cesarean deliveries during prolonged second stage of labor. Int J Gynaecol Obstet. 2019 Feb;144(2):192-8. 
31. Bultez T, Quibel T, Bouhanna P, Popowski T, Resche-Rigon M, Rozenberg P. Angle of fetal head progression measured using transperineal ultrasound as a predictive factor of vacuum extraction failure. Ultrasound Obstet Gynecol. 2016 Jul;48(1):86-91.

32. Eggebo TM, Hassan WA, Salvesen KA, Torkildsen EA, Ostborg TB, Lees CC. Prediction of delivery mode by ultrasound-assessed fetal position in nulliparous women with prolonged first stage of labor. Ultrasound Obstet Gynecol. 2015;46(5):606-10.

33. Mohan A, Mittal P, Bharti R, Grover SB, Suri J, Mohan U. Assessment of labor progression by intrapartum ultrasonography among term nulliparous women. Int J Gynaecol Obstet. 2019 Oct;147(1):78-82.

34. Tutschek B, Torkildsen EA, Eggebo TM. Comparison between ultrasound parameters and clinical examination to assess fetal head station in labor. Ultrasound Obstet Gynecol. 2013;41(4):425-9.

35. Pizzicaroli C, Montagnoli C, Simonelli I, Frigo MG, Valensise H, Segatore MF, et al. Ultrasonographic evaluation of the second stage of labor. Predictive parameters for a successful vaginal delivery with or without neuraxial analgesia: a pilot study. J Ultrasound. 2018 Mar;21(1):41-52.

36. Akmal S, Tsoi E, Kametas N, Howard R, Nicolaides KH. Intrapartum sonography to determine fetal head position. Journal of maternal-fetal and neonatal medicine. 2002;12(3):172-7.

37. Akmal S, Tsoi E, Howard R, Osei E, Nicolaides KH. Investigation of occiput posterior delivery by intrapartum sonography. Ultrasound Obstet Gynecol. 2004;24(4):425-8.

38. Napolitano R, Dhami J, Ohuma EO, Ioannou C, Conde-Agudelo A, Kennedy SH, et al. Pregnancy dating by fetal crown-rump length: a systematic review of charts. BJOG. 2014 Apr;121(5):556-65.

39. Eggebo TM, Wilhelm-Benartzi C, Hassan WA, Usman S, Salvesen KA, Lees CC. A model to predict vaginal delivery in nulliparous women based on maternal characteristics and intrapartum ultrasound. Am J Obstet Gynecol. 2015 2015/09/01/;213(3):e361-e6.

40. Souka AP, Haritos T, Basayiannis K, Noikokyri N, Antsaklis A. Intrapartum ultrasound for the examination of the fetal head position in normal and obstructed labor. Journal of maternal-fetal and neonatal medicine. 2003 Jan;13(1):59-63.

41. Benavides L, Wu JM, Hundley AF, Ivester TS, Visco AG. The impact of occiput posterior fetal head position on the risk of anal sphincter injury in forceps-assisted vaginal deliveries. Am J Obstet Gynecol. 2005 May;192(5):1702-6.

42. Vitner D, Paltieli Y, Haberman S, Gonen R, Ville Y, Nizard J. Prospective multicenter study of ultrasound-based measurements of fetal head station and position throughout labor. Ultrasound Obstet Gynecol. 2015 Nov;46(5):611-5.

43. Peregrine E, O'Brien P, Jauniaux E. Impact on delivery outcome of ultrasonographic fetal head position prior to induction of labor. Obstet Gynecol. 2007 Mar;109(3):618-25.

44. Blanc-Petitjean P, Le Ray C, Lepleux F, De La Calle A, Dreyfus M, Chantry AA. Factors affecting rotation of occiput posterior position during the first stage of labor. J Gynecol Obstet Hum Reprod. 2018;47(3):119-25.

45. Eggebo TM, Hassan WA, Salvesen K, Lindtjorn E, Lees CC. Sonographic prediction of vaginal delivery in prolonged labor: a two-center study. Ultrasound Obstet Gynecol. 2014 Feb;43(2):195-201.

46. Toh-Adam R, Srisupundit K, Tongsong T. Short stature as an independent risk factor for cephalopelvic disproportion in a country of relatively small-sized mothers. Arch Gynecol Obstet. 2012 Jun;285(6):1513-6.

47. Burke N, Burke G, Breathnach F, McAuliffe F, Morrison J, Turner M, et al. Prediction of cesarean delivery in the term nulliparous woman: results from the prospective, multicenter Genesis study. American journal of obstetrics 
gynecology. 2017;216(6):598.e1-.e11.

Table 1 Maternal and newborn characteristics of participants

\begin{tabular}{|c|c|c|}
\hline Variables & Variables & Findings \\
\hline Maternal age, y, mean $\pm \mathrm{SD}$ & Maternal age, $\mathrm{y}$, mean $\pm \mathrm{SD}$ & $29.0 \pm 3.2$ \\
\hline$[?] 35, \mathrm{n}(\%)$ & {$[?] 35, \mathrm{n}(\%)$} & $33(5.4 \%)$ \\
\hline Maternal height, $\mathrm{cm}$, mean $\pm \mathrm{SD}$ & Maternal height, $\mathrm{cm}$, mean $\pm \mathrm{SD}$ & $160.8 \pm 4.8$ \\
\hline Maternal weight, kg, mean $\pm \mathrm{SD}$ & Maternal weight, kg, mean $\pm \mathrm{SD}$ & $67.5 \pm 8.6$ \\
\hline Body mass index, $\mathrm{kg} / \mathrm{m}^{2}$, mean $\pm \mathrm{SD}$ & Body mass index, $\mathrm{kg} / \mathrm{m}^{2}$, mean $\pm \mathrm{SD}$ & $26.1 \pm 2.9$ \\
\hline Overweight, n (\%) & Overweight, n (\%) & $382(62.2 \%)$ \\
\hline Gestational age at delivery, weeks, mean $\pm \mathrm{SD}$ & Gestational age at delivery, weeks, mean $\pm \mathrm{SD}$ & $39.6 \pm 1.0$ \\
\hline \multirow[t]{3}{*}{ Gestational pathology, n (\%) } & Gestational diabetes mellitus, $\mathrm{n}(\%)$ & $93(15.1 \%)$ \\
\hline & Gestational hypertensive disorder, n (\%) & $34(5.5 \%)$ \\
\hline & Intrahepatic cholestasis of pregnancy, n (\%) & $13(2.1 \%)$ \\
\hline \multirow[t]{3}{*}{ Fetal head position at inclusion } & Occiput anterior, $\mathrm{n}(\%)$ & $283(46.1 \%)$ \\
\hline & Occiput transverse, n (\%) & $172(28.0 \%)$ \\
\hline & Occiput posterior, n (\%) & $159(25.9 \%)$ \\
\hline Premature rupture of membranes, n (\%) & Premature rupture of membranes, n (\%) & $155(25.2 \%)$ \\
\hline Epidural, n (\%) & Epidural, n (\%) & $557(90.7 \%)$ \\
\hline Induction of labor, n (\%) & Induction of labor, n (\%) & $234(38.1 \%)$ \\
\hline Augmentation, n (\%) & Augmentation, n (\%) & $411(66.9 \%)$ \\
\hline \multirow[t]{2}{*}{ Delivery mode } & Vaginal delivery, n (\%) & $524(85.3 \%)$ \\
\hline & Cesarean delivery, n (\%) & $90(14.7 \%)$ \\
\hline Birth weight, g, mean \pm SD & Birth weight, g, mean \pm SD & $3414.0 \pm 372.8$ \\
\hline Newborn gender, male, n (\%) & Newborn gender, male, n (\%) & $326(53.1 \%)$ \\
\hline Apgar 1 min, median (range) & Apgar 1 min, median (range) & $10(3-10)$ \\
\hline Apgar 5 min, median (range) & Apgar 5 min, median (range) & $10(5-10)$ \\
\hline Meconium amniotic fluid, n (\%) & Meconium amniotic fluid, n (\%) & $98(16.0 \%)$ \\
\hline 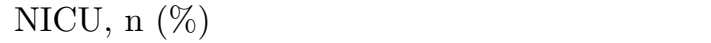 & NICU, n (\%) & $58(9.4 \%)$ \\
\hline
\end{tabular}

Overweight: Body mass index [?]25 kg/ $/ \mathrm{m}^{2}$; NICU, Admission to neonatal intensive care unit.

Table 2 The angle of progression (AoP), head-perineum distance (HPD) and midline angle (MLA) at different time points, according to the mode of delivery

\begin{tabular}{|c|c|c|c|c|c|}
\hline $\operatorname{HPD}(\mathrm{cm})$ & $P$ value & $<0.001$ & $<0.001$ & 0.003 & - \\
\hline & Cesarean delivery & $\begin{array}{l}5.16 \pm 0.89 \\
(\mathrm{n}=90)\end{array}$ & $\begin{array}{l}5.02 \pm 1.01 \\
(\mathrm{n}=40)\end{array}$ & $\begin{array}{l}4.81 \pm 0.55 \\
(\mathrm{n}=10)\end{array}$ & - \\
\hline & Vaginal delivery & $\begin{array}{l}4.57 \pm 0.97 \\
(\mathrm{n}=524)\end{array}$ & $\begin{array}{l}4.09 \pm 1.17 \\
(\mathrm{n}=268)\end{array}$ & $\begin{array}{l}3.69 \pm 1.15 \\
(\mathrm{n}=98)\end{array}$ & $\begin{array}{l}3.39 \pm 0.93 \\
(\mathrm{n}=16)\end{array}$ \\
\hline \multirow[t]{3}{*}{$\operatorname{MLA}\left({ }^{\circ}\right)$} & $\mathrm{P}$ value & 0.201 & $<0.001$ & 0.004 & - \\
\hline & Cesarean delivery & $\begin{array}{l}60.09 \pm 27.93 \\
(\mathrm{n}=86)\end{array}$ & $\begin{array}{l}68.18 \pm 25.49 \\
(\mathrm{n}=40)\end{array}$ & $\begin{array}{l}63.18 \pm 30.79 \\
(\mathrm{n}=10)\end{array}$ & - \\
\hline & Vaginal delivery & $\begin{array}{l}55.27 \pm 27.36 \\
(\mathrm{n}=518)\end{array}$ & $\begin{array}{l}47.42 \pm 27.36 \\
(\mathrm{n}=268)\end{array}$ & $\begin{array}{l}38.96 \pm 24.37 \\
(\mathrm{n}=98)\end{array}$ & $\begin{array}{l}35.47 \pm 21.60 \\
(\mathrm{n}=16)\end{array}$ \\
\hline \multirow[t]{3}{*}{$\mathrm{AoP}(\operatorname{deg})$} & $\mathrm{P}$ value & $<0.001$ & $<0.001$ & $<0.001$ & - \\
\hline & Cesarean delivery & $105.32 \pm 12.76(\mathrm{n}=90)$ & $\begin{array}{l}110.46 \pm 12.5 \\
(\mathrm{n}=40)\end{array}$ & $\begin{array}{l}111.35 \pm 11.1 \\
(\mathrm{n}=10)\end{array}$ & \\
\hline & Vaginal delivery & $\begin{array}{l}116.06 \pm 16.96 \\
(\mathrm{n}=524)\end{array}$ & $\begin{array}{l}128.43 \pm 22.93 \\
(\mathrm{n}=268)\end{array}$ & $\begin{array}{l}138.78 \pm 22.43 \\
(\mathrm{n}=98)\end{array}$ & $\begin{array}{l}143.97 \pm 45.00 \\
(\mathrm{n}=16)\end{array}$ \\
\hline
\end{tabular}




\begin{tabular}{rlllll}
\hline HPD $(\mathrm{cm})$ & P value & $<\mathbf{0 . 0 0 1}$ & $<\mathbf{0 . 0 0 1}$ & $\mathbf{0 . 0 0 3}$ & - \\
\hline & Time point & T1 & T2 & T3 & T4 \\
\hline
\end{tabular}

Table 3 Final logistic regression models to predict spontaneous fetal occiput rotation and vaginal delivery

\begin{tabular}{llll}
\hline Variables in the equation & $\mathrm{aOR}$ & $95 \% \mathrm{CI}$ & $P$ value \\
\hline spontaneous rotation model & spontaneous rotation model & spontaneous rotation model & spontaneous rotation model \\
Midline angle & 1.019 & $1.007-1.031$ & $\mathbf{0 . 0 0 2}$ \\
Maternal height & 1.083 & $1.010-1.162$ & $\mathbf{0 . 0 2 6}$ \\
Constant & -12.634 & & \\
Delivery model & Delivery model & Delivery model & Delivery model \\
Angle of progression & 1.052 & $1.034-1.071$ & $<\mathbf{0 . 0 0 1}$ \\
Maternal height & 1.134 & $1.075-1.195$ & $<\mathbf{0 . 0 0 1}$ \\
Constant & -23.944 & & \\
\hline
\end{tabular}

aOR, adjusted odds ratio; CI, confidence interval.

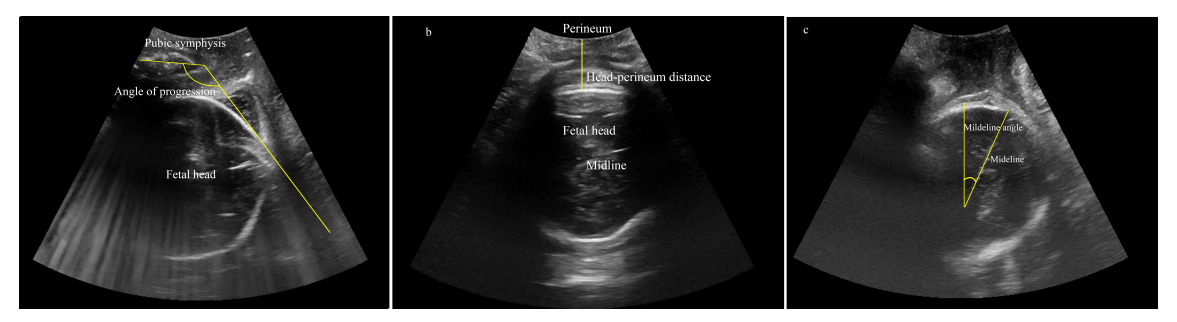



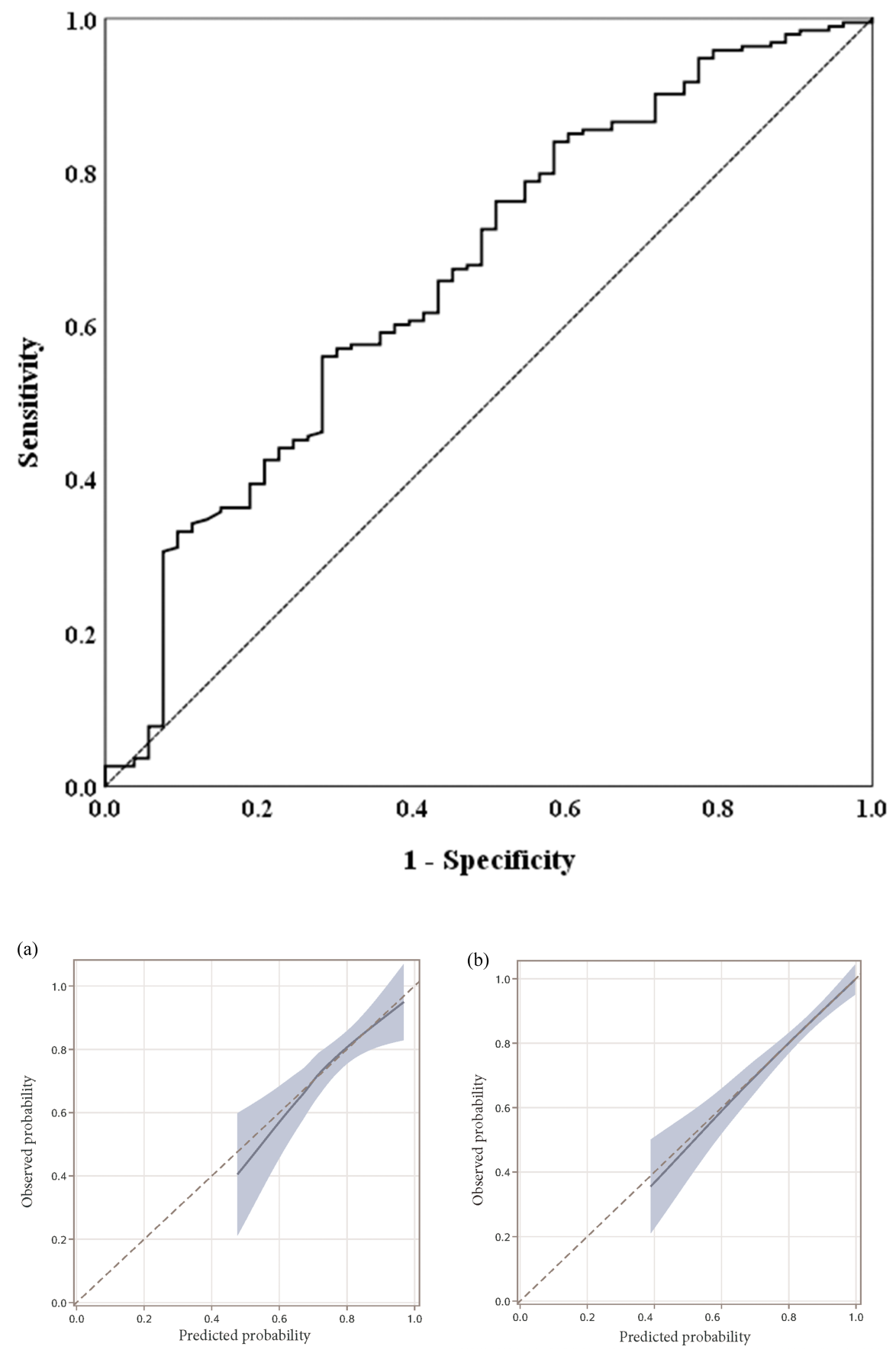


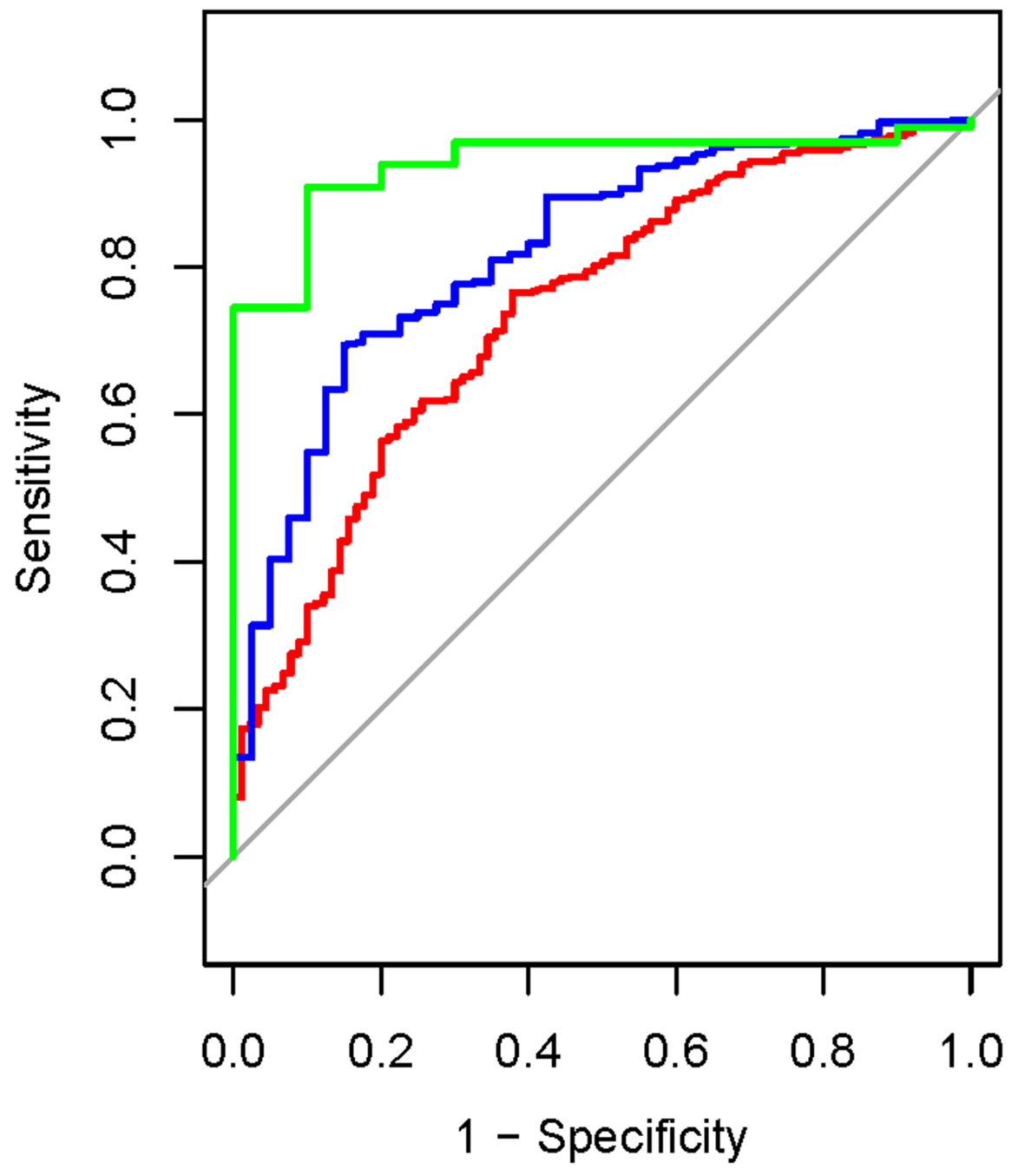




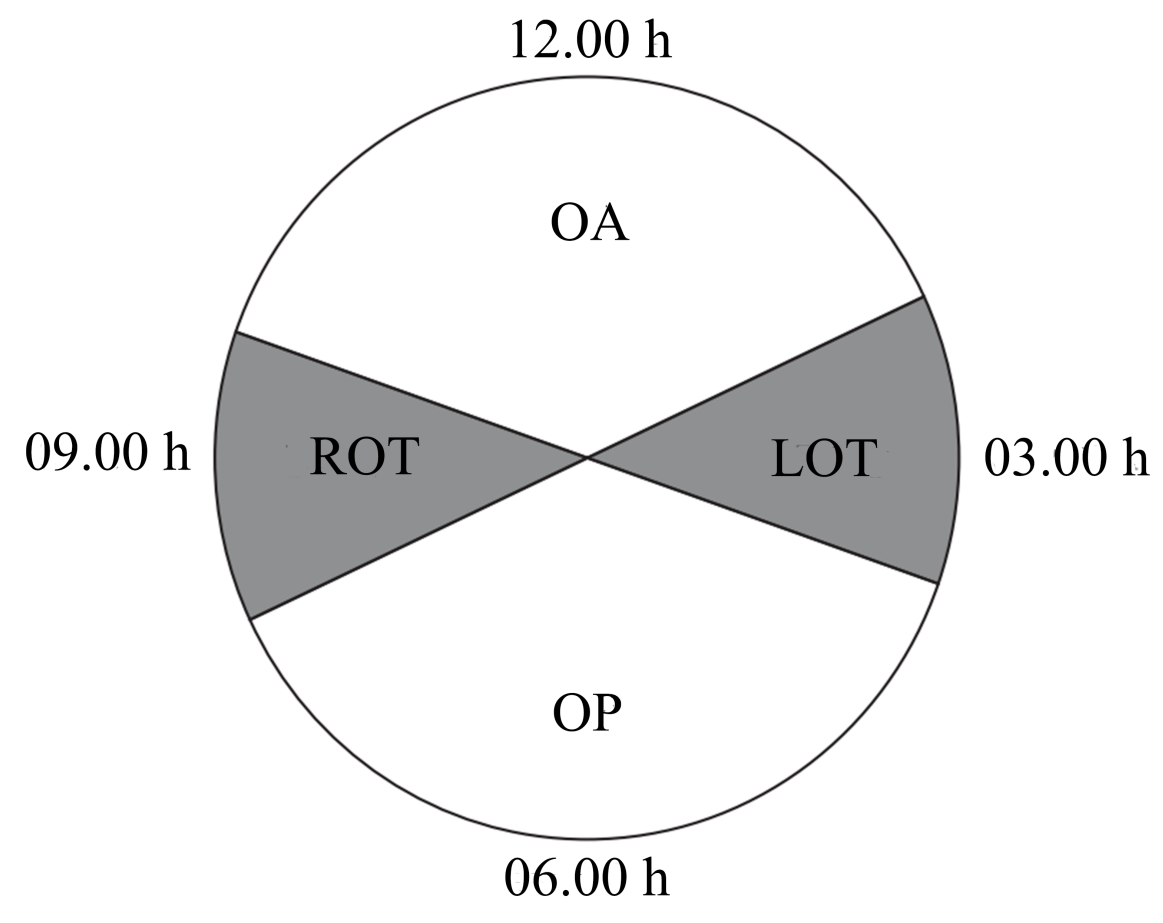




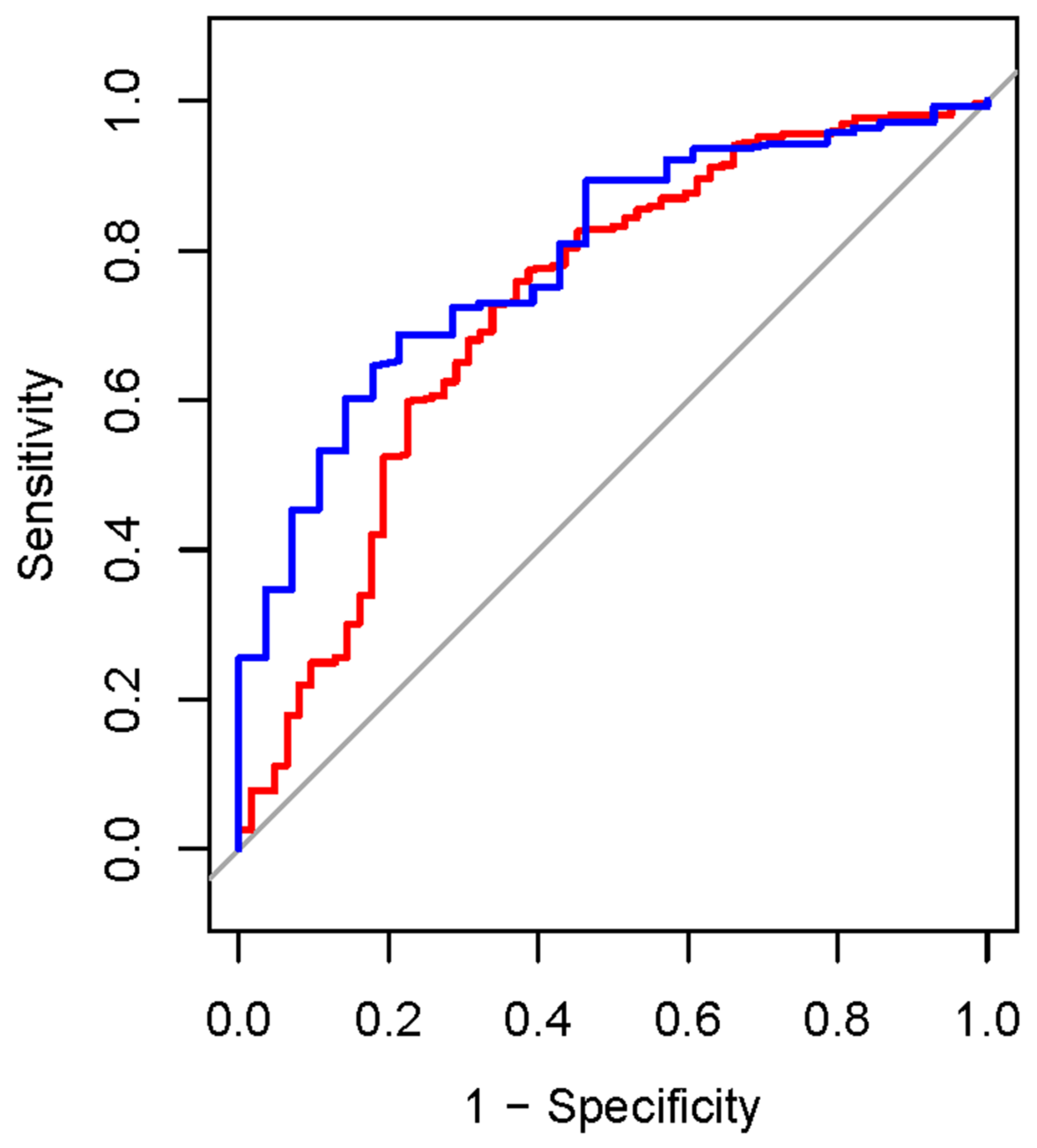

